\title{
T-cell apoptosis induced by intratumoral activated hepatic stellate cells is associated with lung metastasis in hepatocellular carcinoma
}

\author{
YUN-HONG XIA ${ }^{1}$, ZHI-MING WANG ${ }^{2}$, RONG-XIN CHEN ${ }^{2}$, \\ SHENG-LONG YE ${ }^{2}$, RUI-XIA SUN ${ }^{2}$, QIONG XUE ${ }^{2}$ and YONG HUANG ${ }^{1}$ \\ ${ }^{1}$ Department of Oncology, Hefei Second People's Hospital, Anhui Medical University, Hefei 230011; \\ ${ }^{2}$ Liver Cancer Institute, Zhongshan Hospital, Fudan University, Shanghai 200032, P.R. China
}

Received April 9, 2013; Accepted May 15, 2013

DOI: 10.3892/or.2013.2571

\begin{abstract}
Profound T cell inhibitory activity of hepatic stellate cells (HSCs) in vitro has recently been described in hepatocellular carcinoma (HCC). In the present study, we investigated the immune inhibitory activity of HSCs in vivo in an orthotopic rat HCC model with lung metastasis. Rats $(\mathrm{n}=24)$ were randomly sacrificed on days $7,14,21$ and 28 $(\mathrm{n}=4$ each). Lung tissues were stained with hematoxylin and eosin. Liver sections were stained for immunofluorescence analysis. T-cell apoptosis was detected using double staining for terminal deoxynucleotidyl transferase-mediated dUTP nick-end labeling (TUNEL). Staining revealed marked and continuous accumulation of $\alpha$-smooth muscle actin with tumor progression after orthotopic tumor implantation in rat liver. $\mathrm{T}$ lymphocyte numbers gradually increased following tumor progression, and subset analysis revealed an increase in the distribution of liver $\mathrm{CD} 8^{+}$and $\mathrm{CD} 4^{+} \mathrm{T}$ cells. Double staining for CD3 and TUNEL demonstrated T-cell apoptosis. Apoptotic $\mathrm{T}$ cells were more frequent in the HCC livers compared to the normal livers, and were spatially associated with intratumoral activated HSCs (tHSCs), suggesting a direct interaction. T-cell apoptosis was more frequently induced in the co-cultures of activated splenic $\mathrm{T}$ cells(aT)/tHSCs compared to aT/quiescent (q) HSCs or qT/tHSCs. tHSCs were positively correlated with T-cell apoptosis, and the percentage of T-cells undergoing apoptosis was positively correlated with the number of lung metastasis nodules. T-cell apoptosis may be promoted via an interaction with tHSCs, suggesting that tHSCs regulate $\mathrm{T}$ cells and contribute to lung metastasis in HCC.
\end{abstract}

Correspondence to: Professor Sheng-Long Ye, Liver Cancer Institute, Zhongshan Hospital, Fudan University, Shanghai 200032, P.R. China

E-mail: slye@shmu.edu.cn

Key words: hepatocellular carcinoma, hepatic stellate cell, T lymphocyte, apoptosis, metastasis

\section{Introduction}

The immune microenvironment, biology and prognosis of hepatocellular carcinoma (HCC) have recently been the focus of extensive research. Local cellular immune status has been shown to correlate with invasion, recurrence and metastasis in HCC (1). The liver's unique immunological properties have also aroused considerable interest (2). Liver fibrosis is the result of chronic liver injury, during which hepatic stellate cells (HSCs) proliferate and differentiate into myofibroblasts and express $\alpha$-smooth muscle actin $(\alpha$-SMA) $(3,4)$. They also express intercellular adhesion molecule 1 (ICAM-1) and vascular cell adhesion molecule 1 (VCAM-1) and secret chemokines through CD40 expression, and thus, played a role in the regulation of lymphocyte recruitment and migration $(5,6)$. Two recent studies confirmed that T-cell apoptosis can be induced in liver fibrosis and is spatially associated with activated HSCs, suggesting a direct interaction between lymphocytes and HSCs in liver $(7,8)$. In vitro and in vivo studies have demonstrated that culture-activated HSCs inhibit the function of $\mathrm{T}$ lymphocytes through the promotion of $\mathrm{T}$-cell apoptosis $(9,10)$.

HCC contains a large number of $\alpha$-SMA positive HSCs (tHSCs), which are correlated with the invasion and metastasis of HCC (11). However, few studies have examined the immunological function of HSCs and the interaction between the lymphocytes and the tHSCs. In addition, the relationship between the T-cell apoptosis and the HCC metastasis remains unclear. In order to investigate the mechanism whereby tHSCs regulate T-cell infiltration in HCC, as well as $\mathrm{HCC}$ metastasis, we established a rat HCC metastasis model, and studied the interactions between the co-cultured T cells and the tHSCs.

\section{Materials and methods}

Tumor cell line and animals. The rat HCC cell line, McA-RH7777 (MRH), was obtained from the American Type Culture Collection (ATCC; Rockville, MD, USA). Buffalo rats (6-8 weeks old) were obtained from the Charles River Laboratories (Davis, CA, USA). All animal studies were conducted in accordance with the animal care 
policy of the Fudan University and the Animal Research Committee.

Rat tumor model. Intrahepatic tumor implantation was carried out according to Yang et al (12) with minor modifications. MRH cells were injected into the flank of Buffalo rats. HCC tissue was recovered from the transplanted rats 1 month after tumor cell injection, and cut into cubes $\sim 2 \times 1 \times 1 \mathrm{~mm}^{3}$. The rats were anesthetized with ketamine. A small subxiphoid midline incision was made to expose the left lateral lobe of the liver. A small superficial incision was made in the liver and a cube (size, $2 \times 1 \times 1 \mathrm{~mm}^{3}$ ) of tumor was transplanted. The liver incision was closed with 7-0 suture to avoid any possible early peritoneal seeding of the HCC. Tumour extensions were determined by ultrasound on days 7, 14,21 and 28 after tumor establishment.

Lung harvesting. Whole lungs of the recipient rats were harvested on days 7, 14, 21 and 28 for quantitation of metastasis as follows. The trachea of the rat was catheterized with a 22-gauge Angiocath (Becton Dickinson Vascular Access, Sandy, UT, USA) and the lungs were insufflated with $15 \%$ India ink solution. The lungs were preserved in Fekette's solution for $24 \mathrm{~h}$, followed by $10 \%$ formalin. The tumor nodules on the surfaces of the lungs and within the lungs were counted under an operating microscope at x10 magnification (13).

Hematoxylin and eosin $(H \& E)$ staining. Cross-sections of liver were checked for the presence of tumor tissue on days 7, 14 , 21 and 28 after intrahepatic tumor transplantation. Rats were randomly selected for sacrifice on days 7, 14, 21 and $28(n=4$ each), respectively. Livers were fixed in formalin, embedded in paraffin, and stained with $\mathrm{H} \& \mathrm{E}$ for histological examination.

Immunofluorescence. Liver biopsies taken at all check-points were incubated overnight at room temperature with phosphatebuffered saline (PBS), 10\% sucrose and $4 \%$ formaldehyde solution. Specimens were frozen at $-70^{\circ} \mathrm{C}$ and $7-\mu \mathrm{m}$-thick frozen sections were prepared using a cryostat (Leica CM3000; Meyer Instruments, Houston, TX, USA). Cellular hyperpermeability was achieved using the $0.3 \%$ Triton (Sigma, Steinheim, Germany). Bovine serum albumin $1 \%$ was used to block nonspecific background staining. Following washing with PBS, the slides were incubated with primary antibody to lymphocyte markers and anti- $\alpha$-SMA rabbit primary monoclonal antibody (mAb) (Roche, Basel, Switzerland) at a dilution of 1:750 for $1 \mathrm{~h}$ at room temperature in the dark, then washed three times with PBS. The secondary antibody Cy-5 (BD Biosciences, Franklin Lakes, NJ, USA) was then added, followed by three washes with PBS. In each double-stained set, a single lymphocyte subset was stained using anti- $\alpha$-SMA. Fluoresceine isothiocyanate (FITC)-conjugated mouse anti-rat CD4 and allophycocyanin (APC)-conjugated mouse anti-rat CD8 cell mAbs (BD Biosciences) were used, respectively. Sections were stacked and covered with Fluoromount-G (Birmingham, AL, USA) to maintain staining and prevent fluorescent bleaching. Sections were then stored at $4^{\circ} \mathrm{C}$ until analysis by confocal microscopy $(14,15)$.

Terminal deoxynucleotidyl transferase-mediated dUTP nick end labeling (TUNEL) method. For the detection of apoptosis, periodate-lysine-paraformaldehyde-fixed cryosections were stained by the TUNEL technique, using an In Situ Apoptosis Detection kit (Roche), according to the manufacturer's instructions. Sections were incubated at $37^{\circ} \mathrm{C}$ for $1 \mathrm{~h}$ with terminal deoxynucleotidyl transferase in the labeling-safe buffer including FITC, and observed under a confocal laser scanning microscope.

Double staining. After TUNEL staining, cryosections were incubated with Cy5-conjugated anti-rat $\alpha$-SMA mAb (1:500 dilution; Roche) or phycoerythrin (PE)-conjugated antirat $\mathrm{CD} 3 \mathrm{mAb}$ (1:100 dilution; Serotec) overnight at room temperature. They were observed under a confocal laser scanning microscope. FITC images and PE or Cy5 images were entered separately into the computer and superimposed using Adobe Photoshop software (Adobe Systems UK, Uxbridge, UK).

Isolation and culture of HSCs. Rats were anesthetized by intraperitoneal injection of ketamine, $10 \mathrm{mg} / 100 \mathrm{~g}$ body weight. HSCs were prepared from the livers of normal Buffalo rats or HCC tissue, as previously reported (16). In brief, the abdominal cavity of the anesthetized animals was opened to canulate the portal vein. The liver was subsequently perfused at a flow rate of $10 \mathrm{ml} / \mathrm{min}$ with Gey's balanced salt solution (GBSS) without $\mathrm{Ca}^{2+}$ and $\mathrm{Mg}^{2+}$ for $10 \mathrm{~min}$, followed by $100 \mathrm{ml}$ of $0.12 \%$ pronase $\mathrm{E}$ (Roche) dissolved in GBSS with $\mathrm{Ca}^{2+}$ and $\mathrm{Mg}^{2+}\left(\mathrm{GBSS}^{+}\right)$for $10 \mathrm{~min}$. Then $100 \mathrm{ml}$ of $0.1 \%$ collagenase (Roche) dissolved in $\mathrm{GBSS}^{+}$was recirculated for $20 \mathrm{~min}$. The normal liver and HCC tissue were then excised, dissected and incubated for $30 \mathrm{~min}$ at $37^{\circ} \mathrm{C}$ with continuous shaking, with $0.04 \%$ pronase $\mathrm{E}, 0.05 \%$ collagenase and $0.002 \%$ DNase I (Sigma) in $100 \mathrm{ml} \mathrm{GBSS}{ }^{+}$. After digestion, the cell suspension was passed through a $0.22-\mu \mathrm{m}$ mesh and centrifuged at $480 \mathrm{x}$ g for $10 \mathrm{~min}$. Subsequently, cells were purified by $8 \%$ Nycodenz (Sigma) gradient centrifugation. HSCs were grown in DMEM medium (Gibco-BRL) containing 10\% fetal calf serum (FCS) before the experiments were performed. Cell viability determined by trypan blue exclusion was $>90 \%$. The purity of quiescent (q) HSCs and tHSCs ranged from 90-95\%, as determined by desmin immunostaining. tHSC activation was determined by $\alpha$-SMA immunostaining. qHSCs and tHSCs were obtained by culture on uncoated plastic dishes for 2 days (17).

Culture of dendritic cells (DCs). Bone marrow cells isolated from F344 rat (Davis, CA, USA) femurs were lysed of red blood cells using red blood cell lysis buffer (Sigma), cultured in RPMI-1640 medium containing 10\% v/v heat-inactivated FCS, $20 \mathrm{mmol} / 1$ hydroxyethylpiperazine- $\mathrm{N}-2$ ethanesulfonic acid, $2 \mathrm{mmol} / 1 \mathrm{~L}$-glutamine, $0.1 \mathrm{mmol} / 1$ non-essential amino acids, $1 \mathrm{mmol} / 1$ sodium pyruvate, $20 \mu \mathrm{mol} / 12$-mercaptoethanol, and antibiotics (100 U/ml penicillin and $100 \mathrm{mg} / \mathrm{ml}$ streptomycin) (subsequently referred to as complete medium) in the presence of rat recombinant granulocyte-macrophage colonystimulating factor $(4 \mathrm{ng} / \mathrm{ml})$ and interleukin-4 $(1,000 \mathrm{U} / \mathrm{ml})$ (both from BD Bioscences). Non-adherent cells were released spontaneously from the proliferating cell clusters, harvested, washed, and resuspended in complete medium, as previously described (18). 
Co-culture of HSCs and splenic T cells. Proliferation of nylon-wool-eluted Buffalo rat spleen T cells $\left(2 \times 10^{5} /\right.$ well in $100 \mu \mathrm{l}$ ) was stimulated via allogeneic DCs in a one-way mixed leukocyte reaction. Non-stimulated (quiescent, qT) and DC-stimulated (activated, aT) splenic T cells were added to qHSCs or tHSCs (1x10\% well) and further incubated for $48 \mathrm{~h}$. Three rats were used for each group. Apoptotic $\mathrm{T}$ cells were identified via double staining with PE-conjugated anti-CD3 $\mathrm{mAb}$ and TUNEL. Following surface CD3 staining, cells were fixed in $4 \%$ paraformaldehyde and permeabilized with $0.1 \%$ Triton X-100 and $0.1 \%$ sodium citrate. The TUNEL reaction mixture from the Cell Death Detection kit (BD Biosciences, San Diego, CA, USA) was then added according to the manufacturer's instructions. Cells incubated with the labeling solution in the absence of terminal transferase were used as negative controls. The percentage of TUNEL-positive lymphocytes was then calculated.

Confocal microscopy and image capture. A confocal laser scanning microscope (14900 Superfusion System; Radnoti, Monrovia, CA, USA) was used to analyze the stained sections. Fifty images were collected from each liver using a charge-coupled device camera (Hall 100) and analyzed using Zeiss LSM Image Browser software. Image processing was performed using Adobe Photoshop software (Adobe Systems UK) (19).

Quantitative analysis of immunopositive cells. Livers taken on days 7, 14, 21 and 28 were examined. Four rats were used per group for each time period and 10 sections were prepared per animal. The relative areas of $\alpha$-SMA-positive cells and numbers of $\mathrm{CD}^{+}, \mathrm{CD}^{+}$and $\mathrm{TUNEL}^{+}$cells were counted in the HCC area, and the total area in one microscopic field, at a magnification of $\times 100$. One microscopic field at $\times 100$ was $11.4 \mathrm{~mm}^{2}$; a total of $57 \mathrm{~mm}^{2}$ of the liver sections were therefore examined per animal. Cell density was calculated and expressed as cell number per $\mathrm{mm}^{2}(7)$.
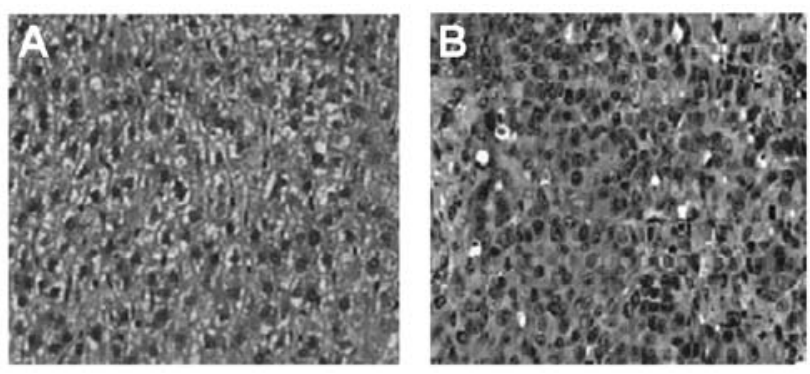

Figure 1. Liver sections from normal and orthotopic hepatocellular carcinoma (HCC) rats. Tumor sections were stained with hematoxylin and eosin on days 7, 14, 21 and 28. Representative sections from (A) normal and (B) $\mathrm{HCC}$ rats are shown. Original magnification, $\mathrm{x} 200$.

Statistical analysis. All statistical analyses were conducted using SPSS 15.0 software. The data were expressed as the means \pm standard deviation (SD). Significant differences were evaluated by unpaired Student's t-tests. Correlations among the density of tHSCs, apoptotic T cells and tumour nodules in the lungs were analyzed using Spearman's rank correlation. $\mathrm{P}<0.05$ (two-tailed) was considered to indicate a statistically significant result.

\section{Results}

Tumor model. Orthotopic HCCs were established with no perioperative complications. All rats (100\%) developed tumors during the observation period (Fig. 1).

Metastatic lung nodules. A previous study demonstrated metastatic lung nodules at day 30 in an orthotopic MRH hepatoma model (13). This observation was confirmed in our experiments; 3 out of $6(50 \%)$ animals had significant evidence of tumor nodules by day 21 (Fig. 2D), and 6 out of 6 (100\%) by day 28 (Fig. 2E). However, tumor nodules were not obvious at days 7 and 14 (Fig. 2B and C). The number of tumor nodules
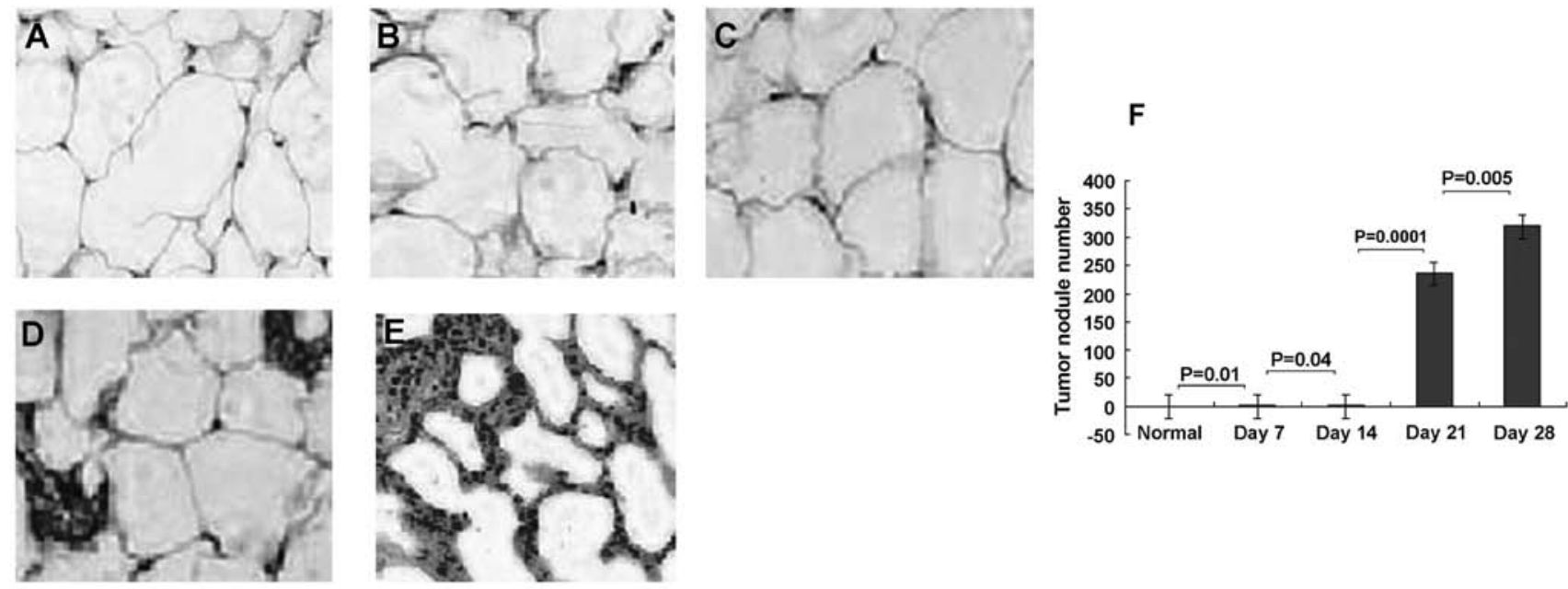

Figure 2. Increased pulmonary tumor nodules in rat model of orthotopic hepatocellular carcinoma (HCC). Lung tissues were sectioned and stained with hematoxylin and eosin on days $0,7,14,21$ and 28 days following HCC. Representative sections from normal and HCC rats are shown. (A) Normal lung tissue. (B) Lung tissue from HCC rats at days 7, (C) 14, (D) 21, and (E) 28. (F) Metastatic lung tumor nodules were then quantified on days 7, 14, 21 and 28. The number of tumor nodules gradually increased with tumor progression. No tumor nodules were found in healthy rats. Results are representative of 2 different experiments with 4 animals in each time subgroup. Results are presented as the means $\pm \mathrm{SD}, \mathrm{P}<0.05$. Original magnification, $\mathrm{x} 200$. 

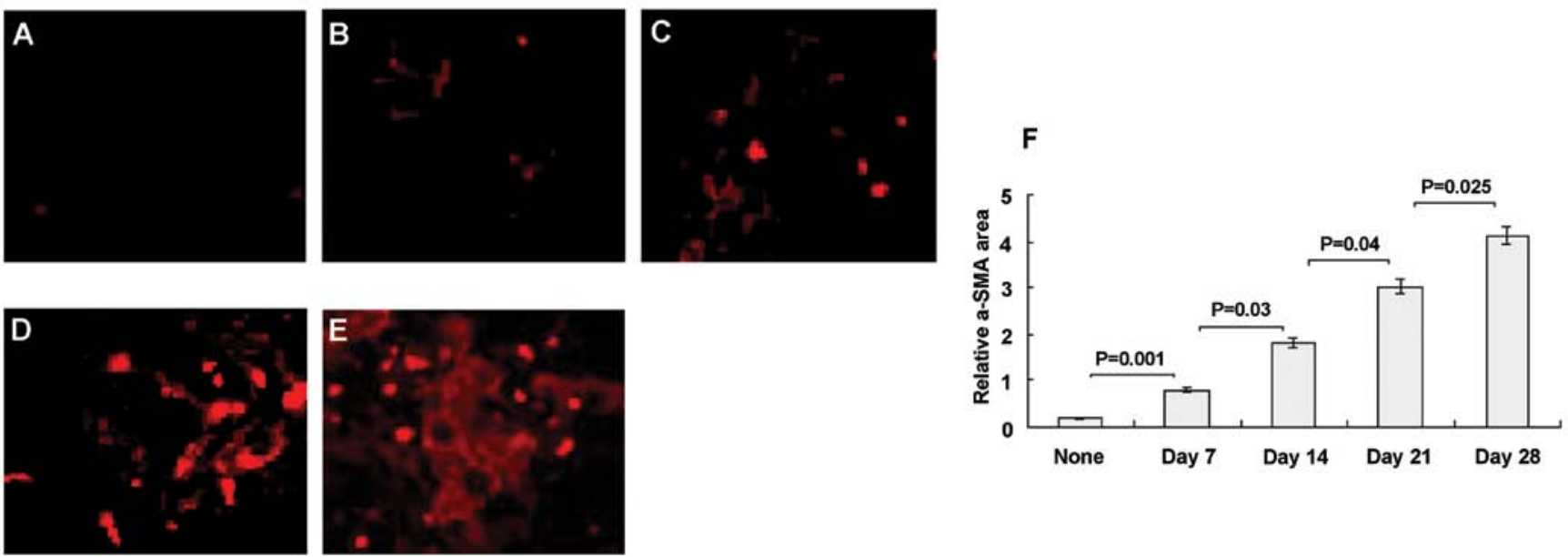

Day 7

$$
\text { Day } 14
$$

Figure 3. Confocal laser scanning microscopy was used to visualize liver sections stained with Cy-5 anti- $\alpha$-SMA antibody. Hepatic stellate cells (HSCs) were stained red. Increased $\alpha$-SMA staining was demonstrated in hepatocellular carcinoma (HCC) tissues on days 7, 14, 21 and 28. (A) Liver sections from naive rats. (B) Liver sections from HCC rats at days 7, (C) 14, (D) 21, and (E) 28. (F) Increased relative area of $\alpha$-SMA following tumor progression. The relative area of stained $\alpha$-SMA cells (expressed as the percentage of total tumor area) was assessed by analyzing 10 stained liver sections per animal. Each field was acquired at x100 magnification and analyzed at the specific channel using a computerized morphometry system. The measured relative area was divided by the field area and multiplied by 100. Results are representative of 2 different experiments with 4 animals in each time subgroup. Results are presented as the mean relative area for all animal groups $\pm \mathrm{SD}, \mathrm{P}<0.05$.
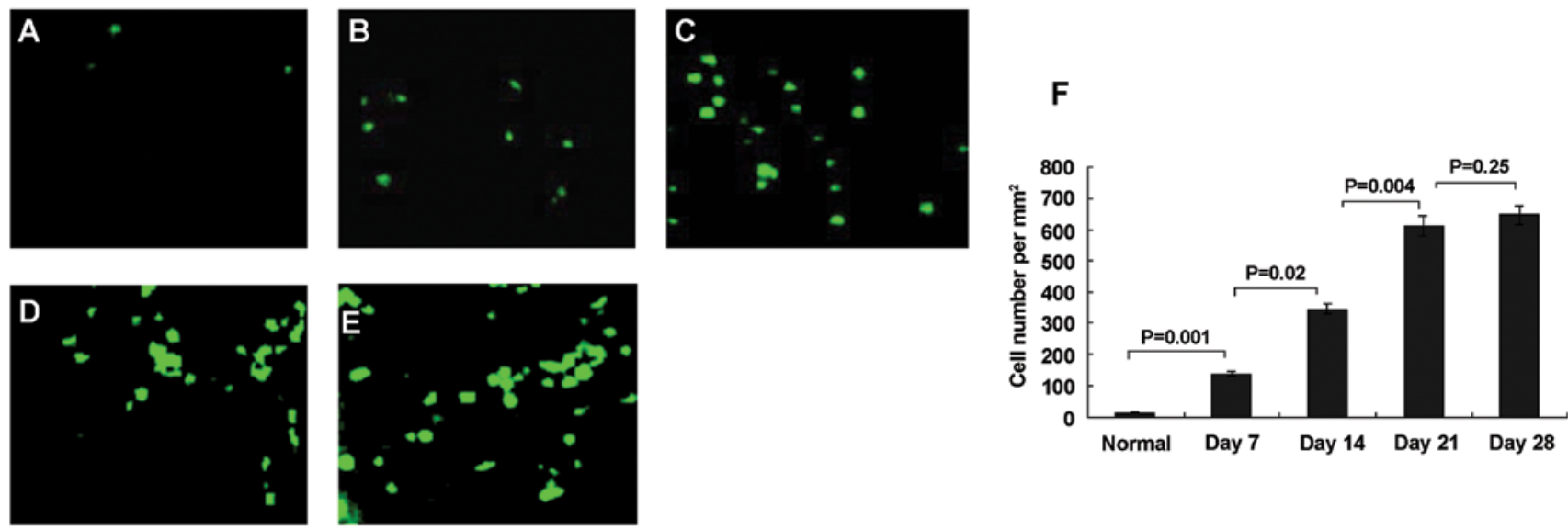

Figure 4. Immunofluorescent staining of normal and hepatocellular carcinoma (HCC) rat livers by FITC-conjugated anti-CD3. Fluorescence microscopy of normal and HCC rat livers at days 7, 14, 21 and 28. (A) Normal liver. (B) HCC livers at days 7, (C) 14, (D) 21, (E) and 28. There were very few T lymphocytes in normal livers, and infiltration in HCC livers increased at days 7, 14, 21 and 28, respectively. (F) Measured relative total T lymphocyte areas in HCC tissue at each time point. Data represent the means $\pm \mathrm{SD}, \mathrm{P}<0.05$. Results are representative of 2 different experiments with 4 animals in each time subgroup. Original magnification, $\mathrm{x} 200$

ranged from 2 to 384 at day 21 , (mean, 234.5 nodules per animal), and from 54 to 579 at day 28 , (mean, 318.7 nodules per animal). There were no tumor nodules in the normal rats, and $0-2$ nodules in $\mathrm{HCC}$ rats on days 7 and 14 (means, 0.23 and 0.42 nodules per animal, respectively). No animals had tumor nodules at extrapulmonary sites. These results demonstrate that the number of tumor nodules gradually increased with tumor progression (Fig. 2F).

HSC activation in HCC. The expression of $\alpha$-SMA (a marker of stellate cell activation) was evaluated in HCC. None of the normal animals showed abnormal $\alpha$-SMA staining (Fig. 3A), except for the normal light staining. In HCC, however, activated HSCs stained positively with Cy-5 anti- $\alpha$-SMA and appeared in situ as red cells (Fig. 3B-E). Although $\alpha-\mathrm{SMA}^{+}$ cells might include myofibroblasts and vascular cells as well as activated HSCs, this remains the gold standard for identification of HSCs (14). The $\alpha$-SMA signal increased markedly with time (Fig. 3B-E). The relative $\alpha$-SMA area was $0.19 \pm 0.12 \%$ in normal animals (Fig. 3F), which increased significantly following $\mathrm{HCC}$ progression, to $0.79 \pm 0.55$ at day $7(\mathrm{P}=0.001)$, $1.81 \pm 1.6$ at day $14(\mathrm{P}=0.03), 3.02 \pm 1.7$ at day $21(\mathrm{P}=0.04)$ and $4.14 \pm 1.9$ at day $28(\mathrm{P}=0.025)$.

T-cell infiltration in HCC rat liver. Figs. 4-6 show representative stained samples from normal liver and from HCC livers at 7, 14, 21 and 28 days. Slight T-cell infiltration occurred at day 7 (Fig. 4B) after tumor implantation, and this infiltration increased at days 14 (Fig. 4C), 21 (Fig. 4D) and 28 (Fig. 4E), respectively. There were fewer $\mathrm{T}$ lymphocytes in normal rat 

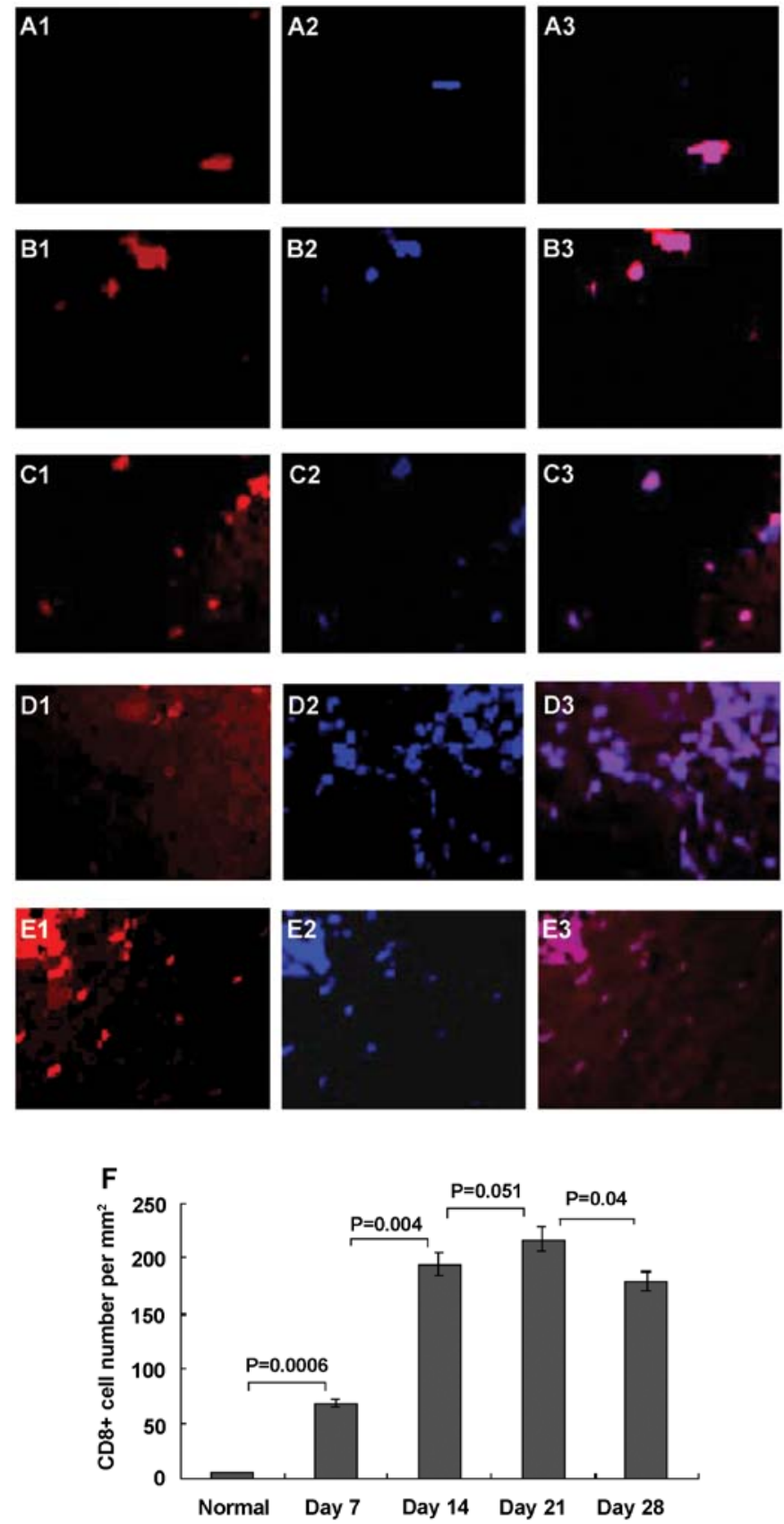

Figure 5. Double staining for $\alpha$-SMA and CD8. Co-localization of $\mathrm{CD}^{+}$cells and intratumoral activated hepatic stellate cells (tHSCs) in situ suggests cell adhesion. Cells were visualized with confocal laser scanning microscopy. Cy-5-conjugated $\alpha$-SMA and APC-conjugated anti-CD8 markers are illustrated with single (A1, B1, C1, D1 and E1, red laser; A2, B2, C2, D2 and E2, blue laser, respectively) and merged stains (A3, B3, C3, D3 and E3, purple cells). Following tumor progression, $\mathrm{CD}^{+}$cells (blue), were only found attached to tHSCs. There were fewer $\mathrm{CD}^{+}$cells in normal rats than in HCC rats, and numbers increased significantly, reaching a plateau within 14 days. $\mathrm{CD}^{+}$cells per unit square peaked at day 21 , and decreased at day 28. (A) Normal liver. (B) HCC liver at days 7, (C) 14, (D) 21 and (E) 28. (F) Measured relative $\mathrm{CD}^{+}$cells at each time point of $\mathrm{HCC}$. Results are representative of 2 different experiments with 4 animals in each time subgroup. Data represent the means $\pm \mathrm{SD}, \mathrm{P}<0.05$. Original magnification, $\mathrm{x} 200$.

livers (Fig. 4A). Immunofluorescence staining demonstrated that the number of $\mathrm{CD} 8^{+}$cells per unit square (Fig. 5A2, B2, C2, D2 and E2) gradually increased at each sequential check point. Following tumor progression, $\mathrm{CD} 8^{+}$cells were
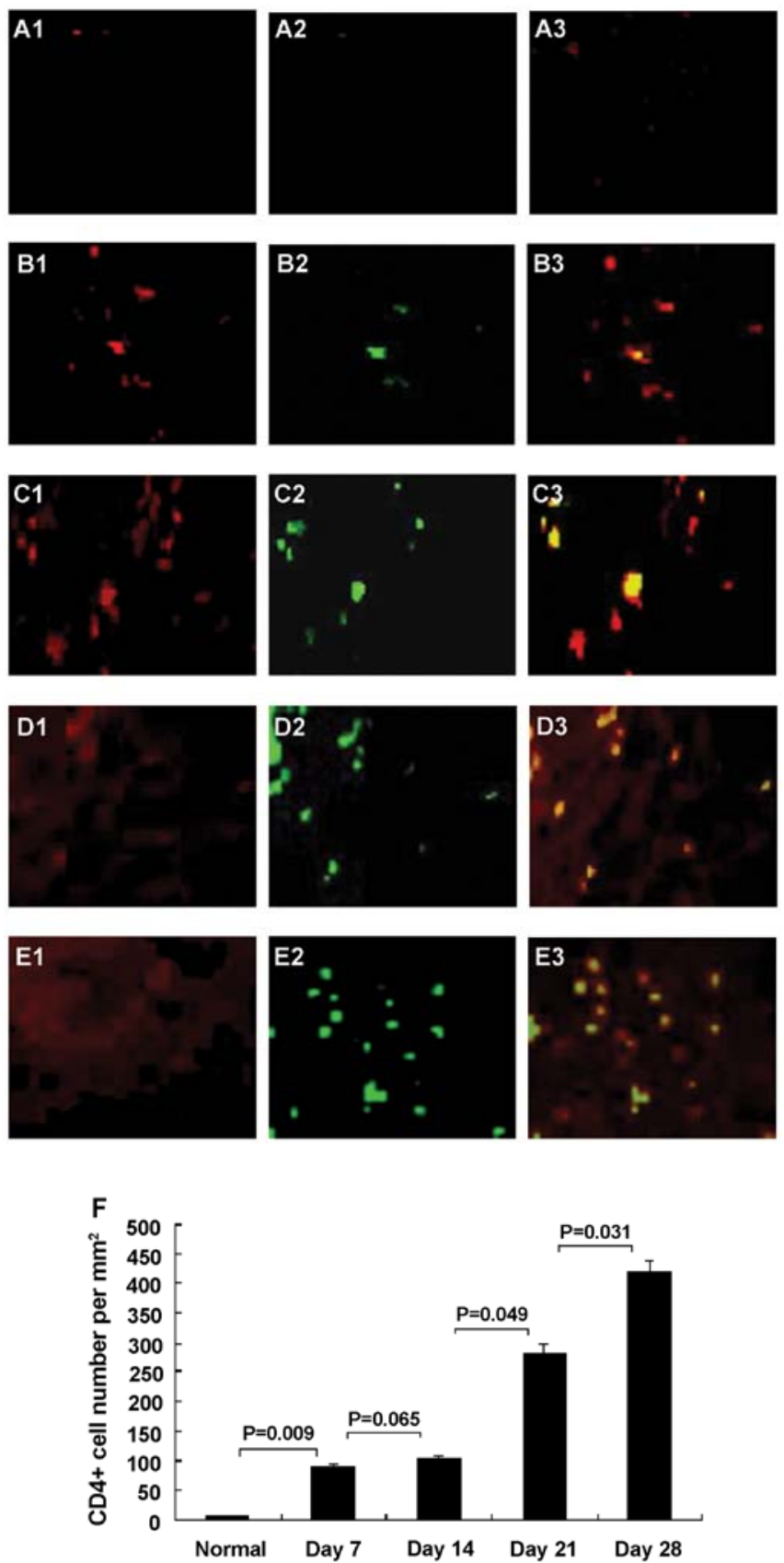

Figure 6. Double-staining for $\alpha$-SMA and CD4. Co-localization of $\mathrm{CD} 4^{+}$cells and intratumoral activated hepatic stellate cells (tHSC) in situ suggests cell adhesion. Cells were visualized with confocal laser scanning microscopy. Cy-5-conjugated $\alpha$-SMA and FITC-conjugated anti-CD4 markers are illustrated with single (A1, B1, C1, D1 and E1, red; A2, B2, C2, D2 and E2, green, respectively) and merged stains (A3, B3, C3, D3 and E3, yellow-green cells). Following tumor progression, $\mathrm{CD}^{+}$cells (green) were only found attached to tHSCs. There were fewer $\mathrm{CD}^{+}$cells in normal rats, and numbers increased significantly at day 7 in HCC rats. No marked increase in CD4 staining was seen at day 14 , but $\mathrm{CD}^{+}$cell numbers were significantly increased at days 21 and 28. (A) Normal liver. (B) HCC liver at days 7, (C) 14, (D) 21 and (E) 28 (F) Measured relative $\mathrm{CD}^{+}$cells at each time point of HCC. Data represent the means $\pm \mathrm{SD}, \mathrm{P}<0.05$. Results are representative of 2 different experiments with 4 animals in each time subgroup. Original magnification, x200.

found very close to tHSCs. Cy-5-conjugated anti- $\alpha$-SMA is shown red (Fig. 5A1, B1, C1, D1 and E1) and APC-conjugated anti-CD8 marker is shown blue in single and merged stains. Areas stained for both CD8 and $\alpha$-SMA markers are purple 

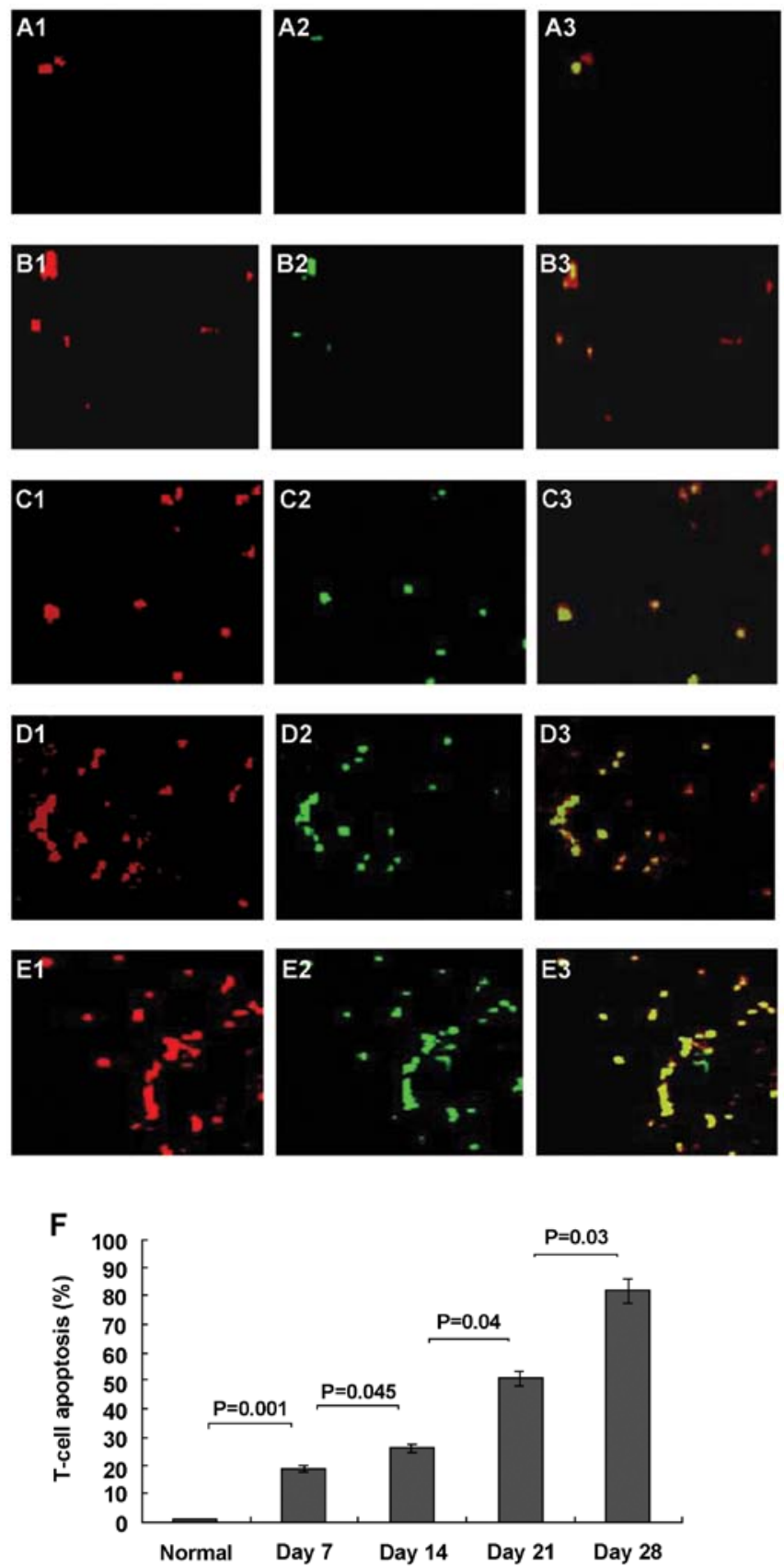

Figure 7. Double staining for T-cell apoptosis in hepatocellular carcinoma (HCC). Some $\mathrm{HCC}$-infiltrating $\mathrm{CD}^{+} \mathrm{T}$ cells also stained positively for TUNEL. Following tumor progression, PE-conjugated anti-CD3- (red, A1, B1, C1, D1 and E1) and TUNEL-stained cells (green, A2, B2, C2, D2 and E2) are shown as single and merged stains. Overlay staining for both CD3 and TUNEL appears yellow-green (A3, B3, C3, D3 and E3), suggesting the existence of $\mathrm{CD}^{+}$cell apoptosis. (A) Normal liver. (B) HCC liver at days 7, (C) 14, (D) 21 and (E) 28. TUNEL $^{+}$cells were rare in normal livers, but increased significantly at days 7 and 14 in HCC livers. The number per unit square of TUNEL ${ }^{+}$cells increased and peaked at day 28. (F) Measured relative $\mathrm{TUNEL}^{+}$cells at each time point of HCC. Data represent the means $\pm \mathrm{SD}$, $\mathrm{P}<0.05$. Results are representative of 2 different experiments with 4 animals in each time subgroup. Original magnification, $\mathrm{x} 200$.

(Fig. 5A3, B3, C3, D3 and E3). These results suggest the existence of direct cell to cell attachment. $\mathrm{CD} 8^{+}$cells were always seen adjacent to tHSCs. There were few $\mathrm{CD}^{+}$cells in normal animals (Fig. 5F), and the numbers increased significantly, reaching a plateau within 14 days. The number of $\mathrm{CD}^{+}$cells
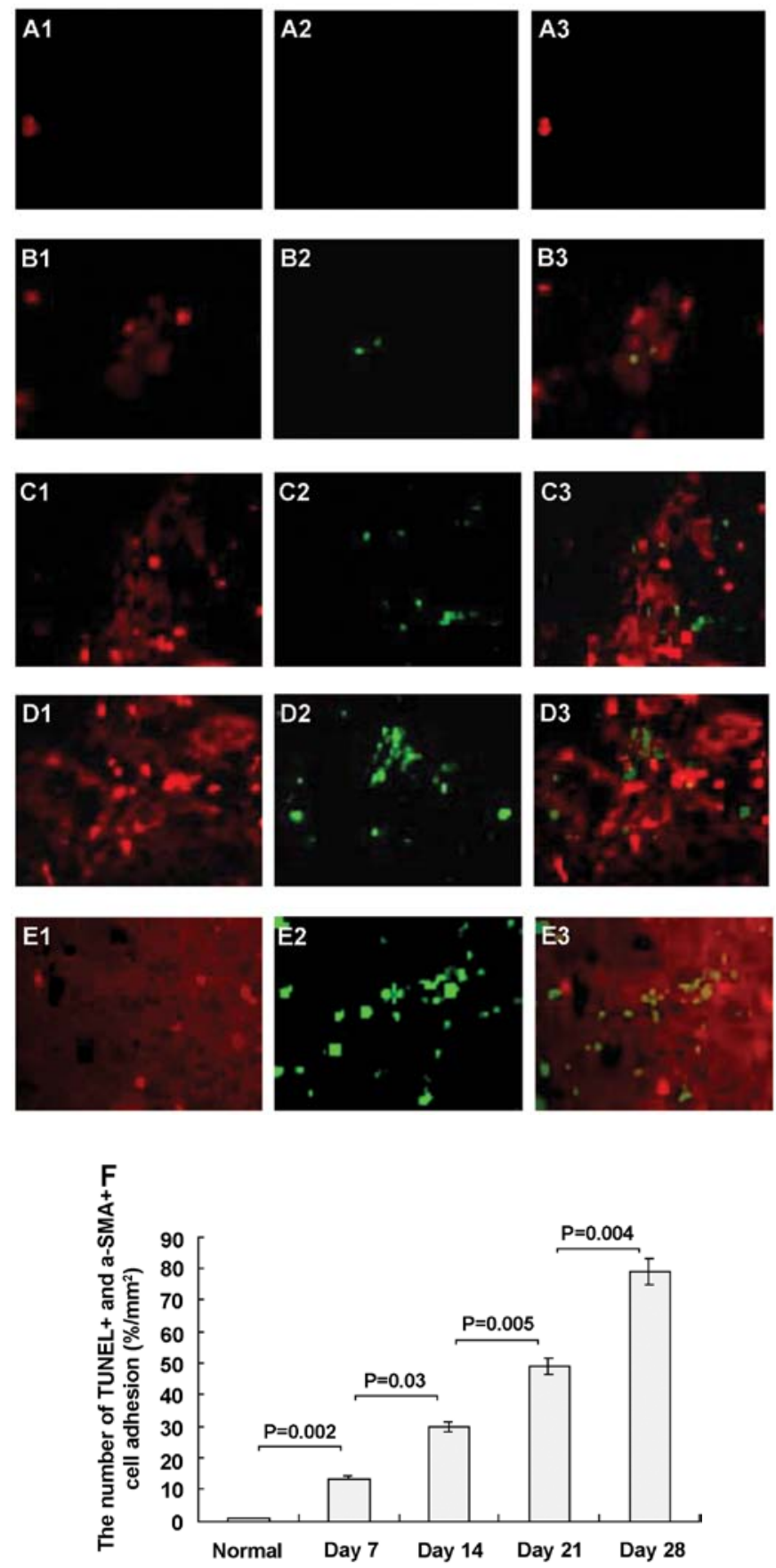

Figure 8. Double staining for TUNEL (yellow-green) and $\alpha$-SMA (red). Following tumor progression, Cy5-conjugated anti- $\alpha$-SMA ${ }^{+}$(red, A1, B1, C1, D1 and E1) and TUNEL ${ }^{+}$cells (green, A2, B2, C2, D2 and E2) are shown as single and merged stains (A3, B3, C3, D3 and E3). Cells stained for both $\alpha$-SMA and TUNEL are yellow-green (A3, B3, C3, D3 and E3), suggesting direct $\alpha-\mathrm{SMA}^{+} \mathrm{HSC}$ and TUNEL ${ }^{+}$cell adhesion. $\alpha-\mathrm{SMA}^{+}$cells were rare in normal rat livers, but increased in $\mathrm{HCC}$ livers. $\mathrm{TUNEL}^{+}$cells were sparse in normal rat livers, but significantly increased in HCC livers at days 7, 14, 21 and 28. TUNEL ${ }^{+}$cells were closely associated with $\alpha-\mathrm{SMA}^{+} \mathrm{HSC}$ in HCC at each time point, and the $\alpha$-SMA ${ }^{+} \mathrm{HSCs}$ and $\mathrm{TUNEL}^{+}$cell adhesion gradually increased. (A) Normal liver. (B) HCC liver at days 7, (C) 14, (D) 21 and (E) 28. (F) Co-localized $\alpha$-SMA ${ }^{+} \mathrm{HSCs}$ and $\mathrm{TUNEL}^{+}$cells per unit square in normal and HCC livers at each time-point. Data represent the means \pm SD, $\mathrm{P}<0.05$. Results are representative of 2 different experiments with 4 animals in each time subgroup. Original magnification, $\mathrm{x} 200$.

per unit square (Fig. 5F) peaked at 21 days, and decreased at 28 days (Fig. 5F). The number of $\mathrm{CD}^{+}$cells per unit square, like $\mathrm{CD} 8^{+}$cells, also gradually increased at each sequential 
check point. $\mathrm{CD}^{+}$cells first appeared in situ at day 7 (Fig. 5F). Cy-5-conjugated anti- $\alpha$-SMA (Fig. 6A1, B1, C1, D1 and E1) and FITC-conjugated anti-CD4 markers (Fig. 6A2, B2, C2, D2 and E2) are illustrated with single (red and green) and merged stains (Fig. 6A3, B3, C3, D3 and E3, yellow-green cells). $\mathrm{CD}^{+}$cells were much less abundant than $\mathrm{CD}^{+}$cells Like $\mathrm{CD}^{+}$cells, however, the CD4 subsets were also mainly found attached to $\alpha$-SMA-positive tHSCs (Fig. 6A3, B3, C3, $\mathrm{D} 3$ and E3). There were fewer $\mathrm{CD}^{+}$cells in normal rats, and they increased significantly at 7 days of HCC (Fig. 6F). No marked increase in CD4 staining was seen at day 14 , but $\mathrm{CD}^{+}$ cell numbers were significantly increased at days 21 and 28 (Fig. 6F).

T-cell apoptosis in HCC. Double staining for CD3 and TUNEL identified some HCC-infiltrating $\mathrm{CD}^{+} \mathrm{T}$ cells that were also positive for TUNEL staining (Fig. 7). Following tumor progression, PE-conjugated anti-CD3- (red; Fig. 7A1, B1, C1, D1 and E1) and TUNEL-stained cells (green; Fig. 7A2, B2, C2, D2 and E2) are illustrated as single and merged stains. Cells stained for both CD3 and TUNEL are yellow-green (Fig. 7B3, C3, D3 and E3). These results suggest the existence of $\mathrm{CD}^{+}$cell apoptosis. TUNEL ${ }^{+}$cells were rare in normal livers (Fig. 7F), but were significantly increased at days 7 and 14 in $\mathrm{HCC}$ livers. The number per unit square of $\mathrm{TUNEL}^{+}$cells increased and peaked at day 28 (Fig. 7F). Double staining for $\alpha$-SMA (red) and TUNEL (yellow-green) revealed no obvious $\alpha-\mathrm{SMA}^{+} / \mathrm{TUNEL}^{+}$cells in normal rat livers (Fig. 8A), but double-stained cells were clearly found in HCC livers at each time-point (Fig. 8B-E). Direct $\alpha-\mathrm{SMA}^{+} \mathrm{HSCs}$ and TUNEL ${ }^{+}$ cell adhesion gradually increased on days 7, 14, 21 and 28. TUNEL $^{+}$cells were closely associated with $\alpha-\mathrm{SMA}^{+}$HSCs at each time point (Fig. 8A3, B3, C3, D3 and E3). Quantitative analysis demonstrated that the percentage of co-localized $\alpha-\mathrm{SMA}^{+}$HSCs and TUNEL ${ }^{+}$cells per unit square gradually increased in the HCC area at each time point, while there was no appreciable increase in normal rat livers (Fig. 8F).

Induction of T-cell apoptosis in co-culture with HSCs. To confirm the results found in HCC sections, HSCs were isolated from normal and HCC livers and cultured. HSCs from the normal livers cultured for 2 days demonstrated quiescent features (qHSCs), with round or star shapes, abundant lipid droplets, and a lack of $\alpha$-SMA expression. HCC HSCs cultured for 2 days (tHSCs) demonstrated activated features (data not shown). We investigated the adhesion of HSCs and $\mathrm{T}$ cells. Light microscopy clearly demonstrated adhesion of DC-stimulated T cells (aT) cells to tHSCs in aT/tHSCs co-culture (Fig. 9C). However, T cells were only slightly associated with HSCs in cultures of qT or aT cells alone (Fig. 9A and B), and in co-cultures of qT cells/tHSCs (Fig. 9D), aT cells/qHSCs (Fig. 9E) and qT/qHSCs (Fig. 9F). We then investigated the inducing role of tHSCs in T-cell apoptosis using co-cultured splenic T cells and tHSCs, and double staining for TUNEL and CD3. Splenic T cells, either non-stimulated (qT) or DC-stimulated (aT), were co-cultured with qHSCs or tHSCs for $24 \mathrm{~h}$. Culture of qT cells alone (Fig. 9A) or aT cells alone (Fig. 9B) for $24 \mathrm{~h}$ showed a very low frequency of apoptosis (Fig. 10A and B). However, when aT cells were co-cultured with tHSCs (Fig. 9C), the former often became round when
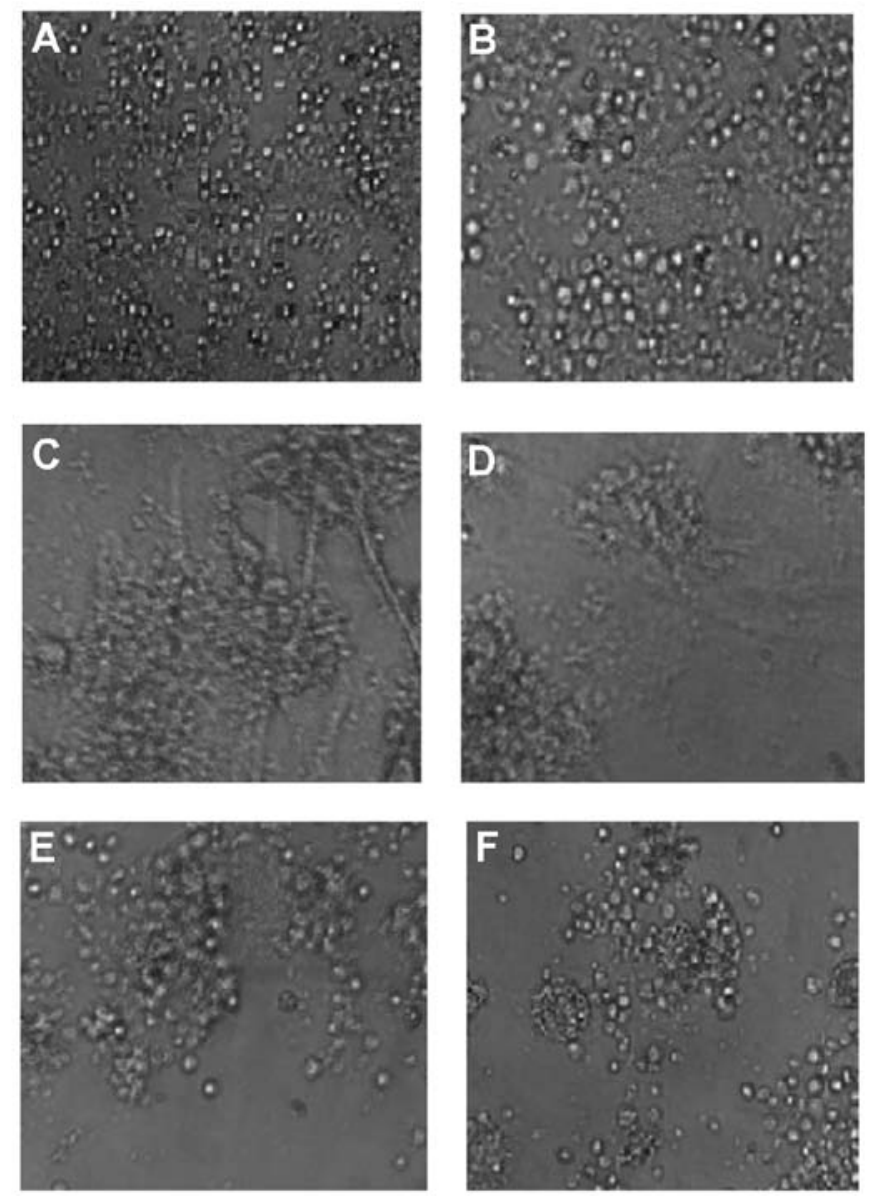

Figure 9. Phase-contrast microscopy of co-culture of HSCs and splenic T lymphocytes at $24 \mathrm{~h}$. (A) Quiescent T lymphocytes alone (qT); (B) activated T lymphocytes alone (aT); (C) intratumoral HSCs (tHSCs) and aT cells; (D) tHSCs and qT lymphocytes; (E) quiescent HSCs (qHSCs) and aT cells; (F) qHSCs and tHSCs. HSCs were prepared by pre-culture of freshly isolated HSCs from normal and HCC livers for 2 days, respectively. Splenic T lymphocytes were prepared by Ficoll gradient centrifugation, and aT cells and qT cells were obtained by in vitro treatment with rat dendritic cells and culture medium alone, respectively. aT cells clearly adhered to tHSCs in aT/tHSC co-cultures. However, qT or aT cells alone, or in co-cultures of qT cells/tHSCs, aT cells/qHSCs and qT/qHSCs, T cells were only slightly associated with HSCs. Results are representative of 3 different experiments. Original magnification, x100.

viewed under a phase-contrast microscope, and stained positive for TUNEL (Fig. 10C). Both cell rounding and TUNEL ${ }^{+}$ staining (Fig. 10D-F) were less frequent in co-cultures of qT cells/tHSCs (Fig. 9D), aT cells/qHSCs (Fig. 9E) and qT cells/qHSCs (Fig. 9F). While the percentage of $\mathrm{TUNEL}^{+}$cells in total lymphocytes adhering to HSCs was low in co-cultures of aT cells/qHSCs and qT cells/tHSCs, it was significantly increased in co-cultures of aT cells/tHSCs (Fig. 10G).

T-cell apoptosis is associated with HCC metastasis. tHSCs became increasingly prominent in HCC livers compared to normal livers, following HCC progression at each time point, accompanied by marked T-cell apoptosis and lung metastasis (Table I). Correlation analysis showed that the number of tHSCs was positively correlated with the percentage of T-cell apoptosis $(\mathrm{r}=0.861, \mathrm{P}<0.05)$ (Fig. 11A), and the percentage of T-cell apoptosis was positively correlated with metastasis in the lungs $(\mathrm{r}=0.911, \mathrm{P}<0.01)$ (Fig. 11B). 

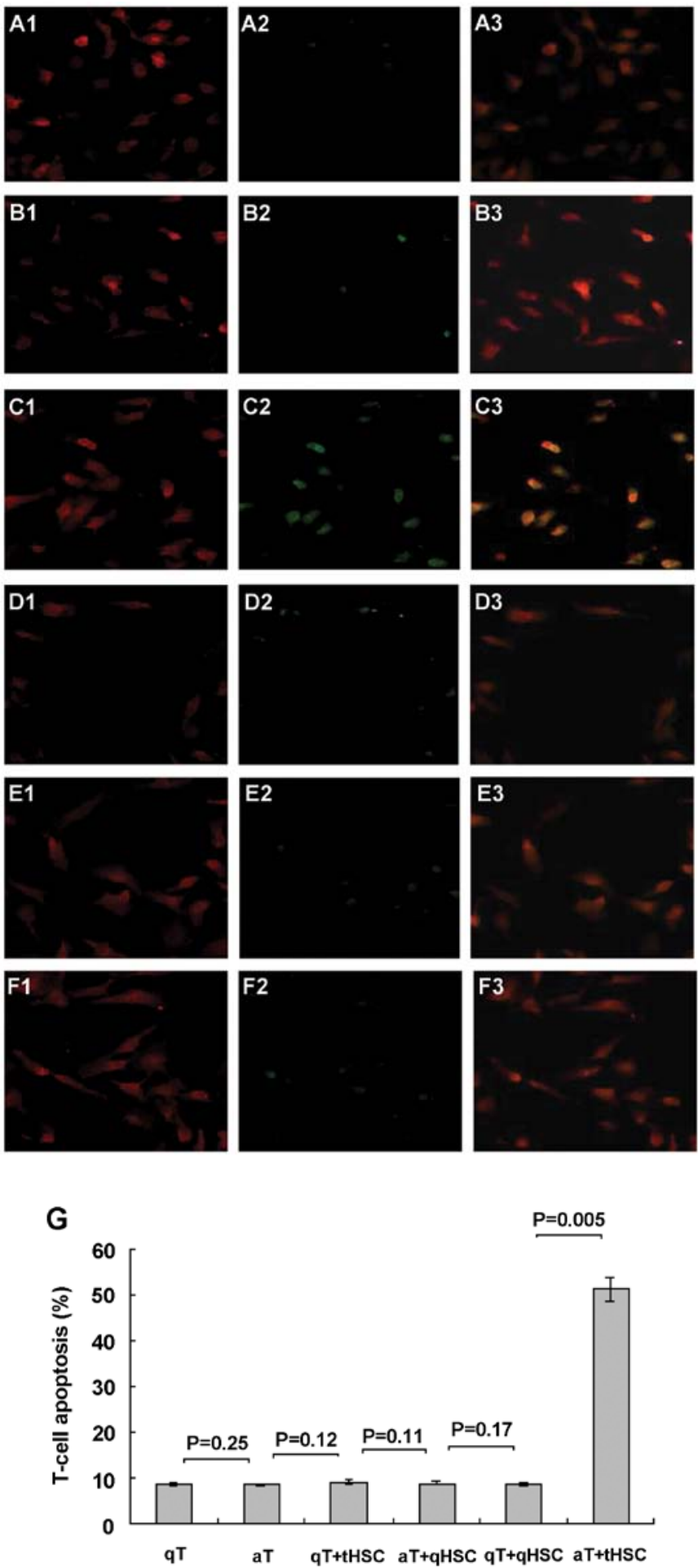

Figure 10. Double staining for TUNEL (green) and CD3 (red) in quiescent or dendritic cell-stimulated activated $\mathrm{T}(\mathrm{aT})$ lymphocytes co-cultured with quiescent (qHSCs) or intratumoral activated HSCs (tHSCs). (A) qT cells alone; (B) aT cells alone; (C) tHSCs/aT cells; (D) tHSCs/qT cells; (E) qHSCs/aT cells; (F) qHSCs/qT cells. PE-conjugated anti-CD3 (red, A1, B1, C1, D1, E1 and F1) and TUNEL (green, A2, B2, C2, D2, E2 and F2) are shown as single and merged stains (A3, B3, C3, D3, E3 and F3). Overlay staining for both CD3 and TUNEL appears yellow-green (A3, B3, C3, D3, E3 and F3), suggesting the existence of TUNEL ${ }^{+} \mathrm{CD} 3$ cells. qT cells (A2) or aT cells (B2) cultured alone for $24 \mathrm{~h}$ showed a very low frequency of apoptosis. However, aT cells co-cultured with tHSCs often stained positive for TUNEL (C2), whereas $\mathrm{TUNEL}^{+}$staining was less frequent in co-cultures of qT cells/tHSCs (D2), aT cells/qHSCs (E2) and qT cells/qHSCs (F2). (G) Percentage of TUNEL ${ }^{+} \mathrm{T}$ lymphocytes. Results are representative of three different experiments. Data represent the means $\pm \mathrm{SD}$, the frequency of apoptosis in aT/tHSC co-cultures compared to all groups, $\mathrm{P}<0.05$. Original magnification, $\mathrm{x} 200$.
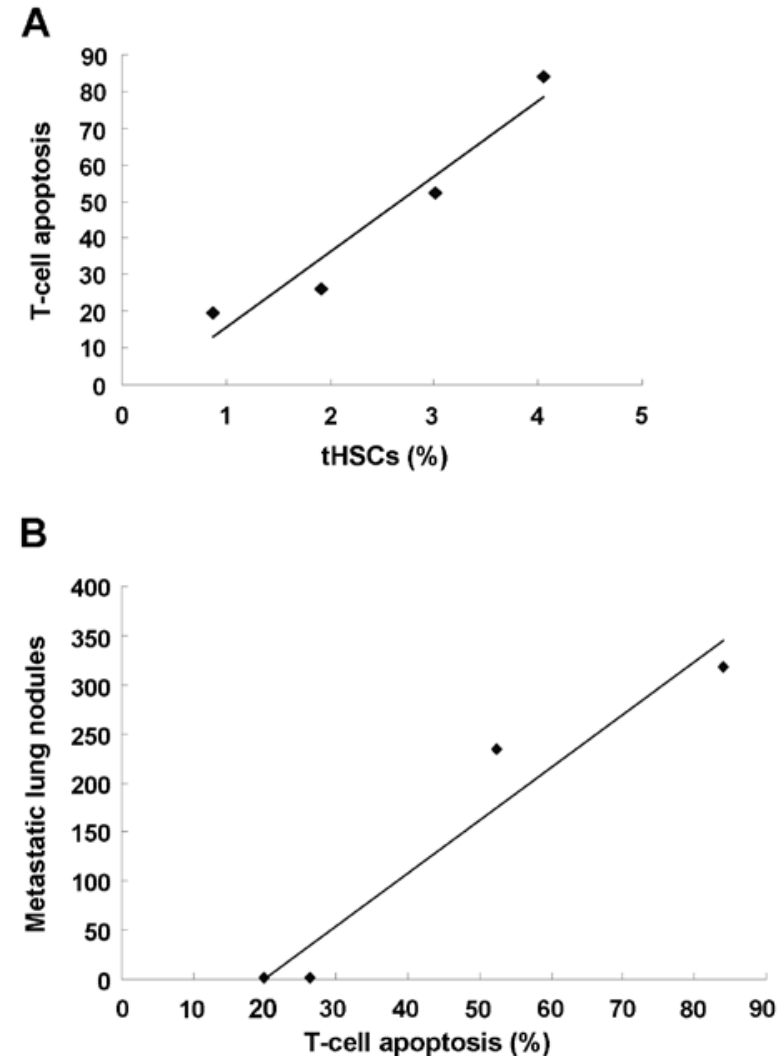

Figure 11. Correlations among the density of tHSCs, apoptotic T cells and tumour nodules in the lungs were analyzed using Spearman's rank correlation. Correlation analysis results are shown. (A) The number of tHSCs was positively correlated with the percentage of $\mathrm{T}$-cell apoptosis $(\mathrm{r}=0.861$, $\mathrm{P}<0.05)$. (B) The percentage of $\mathrm{T}$-cell apoptosis was positively correlated with metastasis in the lungs $(\mathrm{r}=0.911, \mathrm{P}<0.01)$.

Table I. tHSCs, T-cell apoptosis and metastatic lung nodules.

\begin{tabular}{lclc}
\hline & $\begin{array}{c}\text { tHSCs } \\
(\%)\end{array}$ & $\begin{array}{c}\text { T-cell } \\
\text { apoptosis }(\%)\end{array}$ & $\begin{array}{c}\text { Metastatic } \\
\text { lung nodules }\end{array}$ \\
\hline Day 7 $(\mathrm{n}=4)$ & $0.87 \pm 0.14$ & $19.81 \pm 5.33$ & $0.23 \pm 0.92$ \\
Day 14 $(\mathrm{n}=4)$ & $1.92 \pm 0.53$ & $26.32 \pm 11.38$ & $0.42 \pm 0.18$ \\
Day 21 $(\mathrm{n}=4)$ & $3.01 \pm 1.28$ & $52.31 \pm 18.21$ & $234.50 \pm 92.6$ \\
Day 28 $(\mathrm{n}=4)$ & $4.05 \pm 1.97$ & $84.12 \pm 29.65$ & $318.70 \pm 118.5$ \\
\hline
\end{tabular}

tHSCs became increasingly prominent in HCC livers, following HCC progression at each time point, accompanied by marked T-cell apoptosis and lung metastasis. Results are representative of four animal experiments in each time subgroup. Data represent the means \pm SD.

\section{Discussion}

Considerable advances have been made in terms of our understanding of cancer origins. Genetic and cell-biology studies have indicated that the cooperative activity of parenchymal and mesenchymal cells is central to carcinogenesis and cancer progression $(20,21)$. In the liver, hepatocytes represent the major parenchymal cell type, while the mesenchymal compartment is composed of various cell types, including Kupffer cells and HSCs. HSCs are widely accepted as playing a pivotal 
role in hepatic tumorigenesis following liver injury $(22,23)$. HSCs have been previously proposed to exhibit the features of antigen-presenting cells and to stimulate lymphocyte proliferation (24). HSCs transdifferentiate into $\alpha-\mathrm{SMA}^{+}$ myofibroblast-like cells and induce T-cell apoptosis in liver injury (7). T-cell apoptosis induced during inflammation contributes to immune homeostasis in the liver $(25,26)$. HCC is considered to represent a specific type of liver damage, and activated HSCs can promote the proliferation and metastasis of HCC (27). However, the delicate relationship between the immunological characteristics of tHSCs and HCC metastasis is far from clear.

In the present study, we investigated T-cell apoptosis in HCC in an orthotopic rat HCC model, using cubes of tumor transplanted into rat livers (12). We demonstrated that the role of T cells in HCC appeared to be modulated through direct attachment to tHSCs, emphasized by their cell to cell proximity and surface contact. HCC was confirmed by conventional $\mathrm{H} \& \mathrm{E}$ liver staining, and direct contacts between $\mathrm{T}$ lymphocyte subsets and HSCs were manifested in HCC livers. We suggest that lymphocytes migrate into $\mathrm{HCC}$ tissue as a result of HCC progression $(28,29)$, and interact with tHSCs. Confocal imaging revealed significant increases in intrahepatic $\mathrm{CD}^{+}$ and $\mathrm{CD}^{+}$subsets following tumor progression at each time point. These results suggest that all lymphocyte subsets infiltrating into HCC probably interact directly with activated HSCs by adhesion.

T-cell apoptosis was demonstrated by double staining for TUNEL and CD3. Apoptosis of T cells was more common in HCC livers compared to normal livers. T-cell apoptosis was also noted to be spatially associated with tHSCs in HCC, suggesting an inducing role for the latter cells. However, the involvement of other cell types, such as macrophages (30), cytotoxic T cells (31) and tumor cells (32), which are reported to possess apoptosis-inducing functions, could not be excluded. To confirm the inducing role of tHSCs, we therefore, conducted in vitro experiments using co-cultures of aT cells and tHSCs. Apoptosis was increased in these co-cultures, but not in co-cultures of aT cells with qHSCs, or qT cells with tHSCs, indicating that tHSCs are responsible for inducing apoptosis of aT cells. Further studies are planned to investigate the mechanism of T-cell apoptosis with regard to the involvement of cytokine production or cell-receptor expression using this culture system. Because the experiment aimed to demonstrate the requirement for direct contact between lymphocytes and myofibroblast-like cells, we therefore, examined the apoptosis-inducing activity of the culture medium obtained from tHSCs. Supplementation with culture medium from tHSCs did not significantly increase the percentage of T-cell apoptosis, confirming the need for direct contact or close proximity with tHSCs for T-cell apoptosis. These results are in good agreement with the liver-section results. Activation of $\mathrm{T}$ cells has been reported to enhance their interaction with fibroblasts via a CD2-dependent adhesion pathway (33), and this interaction serves to increase the survival of aT cells by inhibiting apoptosis $(34,35)$. The results of the current investigation support this hypothesis; while aT cells cultured without HSCs frequently underwent spontaneous apoptosis, they showed a low frequency of apoptosis in co-culture with qHSCs. Furthermore, apoptosis of T cells was not induced in normal livers containing qHSCs, but was induced in HCC livers containing tHSCs, and in co-culture with tHSCs. The mechanism of T-cell-apoptosis induction by tHSCs is not known. Galectin-1 might be involved in this event, because it is produced by tHSCs but not qHSCs (36), and induces selective elimination of T cells (37). Some data have demonstrated that aT cells use CD44 to undergo apoptosis, and dysregulation of this pathway could lead to increased pathogenesis in a number of diseases, including hepatitis (38). The upregulated expression of B7-H1 (PD-L1, CD274) in activated HSCs can induce T-cell apoptosis (9). It has also been reported that activated HSCs induce transmigration of leukocytes via expression of adhesion molecules such as ICAM-1 and VCAM-1 $(5,39)$. Taken together, the present model demonstrated prominent T-cell infiltration in HCC and indicated that tHSCs play roles in inducing lymphocyte apoptosis in HCC.

The present study indicated that the number of tHSCs in HCC gradually increased at days 7, 14, 21 and 28, with a corresponding progressive increase in the number of $\mathrm{T}$ cells. However, the number of apoptotic $\mathrm{T}$ cells also gradually increased, and lung metastasis ultimately developed. Statistical analysis showed that tHSCs in HCC were positively correlated with T-cell apoptosis, and that the percentage of T-cell apoptosis was positively correlated with the number of lung metastasis nodules. The present research, thus, demonstrated tHSC-related T-cell apoptosis, suggesting that tHSC immunosuppression in HCC may indirectly promote the growth and metastasis of HCC.

In conclusion, the findings of the present study suggest that T lymphocytes extravasate and accumulate in HCC tissues during tumor progression. They attach directly to tHSCs and are induced to undergo apoptosis through interactions with tHSCs, contributing to lung metastasis of HCC. The present study provides the first evidence for an immunological function for tHSCs in HCC. However, further studies are needed to confirm these results and to identify new targets for inhibiting metastasis of HCC.

\section{Acknowledgements}

The authors wish to thank Zen Haiyin from the Department of Pathology, Zhongshan Hospital, Fudan University, for her technical help in preparing histological sections. This research was funded by the National Key Basic Research Development Program (973) project of China (2004CB518708) and the National Natural Science Foundation of China (81000909).

\section{References}

1. Unitt E, Rushbrook SM, Marshall A, et al: Compromised lymphocytes infiltrate hepatocellular carcinoma: the role of T-regulatory cells. Hepatology 41: 722-730, 2005.

2. Mehal WZ, Azzaroli F and Crispe IN: Immunology of the healthy liver: old questions and new insights. Gastroenterology 120: 250-260, 2001.

3. Friedman SL: Molecular regulation of hepatic fibrosis, an integrated cellular response to tissue injury. J Biol Chem 275: 2247-2250, 2000.

4. Friedman SL: Liver fibrosis - from bench to bedside. J Hepatol 38: S38-S53, 2003.

5. Knittel T, Dinter C, Kobold D, et al: Expression and regulation of cell adhesion molecules by hepatic stellate cells (HSC) of rat liver: involvement of HSC in recruitment of inflammatory cells during hepatic tissue repair. Am J Pathol 154: 153-167, 1999. 
6. Schwabe RF, Schnabl B, Kweon YO and Brenner DA: CD40 activates NF- $\mathrm{KB}$ and $\mathrm{c}$-Jun N-terminal kinase and enhances chemokine secretion on activated human hepatic stellate cells. J Immunol 166: 6812-6819, 2001.

7. Kobayashi S, Seki S, Kawada N, et al: Apoptosis of T cells in the hepatic fibrotic tissue of the rat: a possible inducing role of hepatic myofibroblast-like cells. Cell Tissue Res 311: 353-364, 2003.

8. Muhanna N, Horani A, Doron S and Safadi R: Lymphocytehepatic stellate cell proximity suggests a direct interaction. Clin Exp Immunol 148: 338-347, 2007.

9. Yu MC, Chen $\mathrm{CH}$, Liang X, et al: Inhibition of T-cell responses by hepatic stellate cells via B7-H1-mediated T-cell apoptosis in mice. Hepatology 40: 1312-1321, 2004.

10. Chen $\mathrm{CH}$, Kuo LM, Chang Y, et al: In vivo immune modulatory activity of hepatic stellate cells in mice. Hepatology 44: 1171-1181, 2006

11. Kurogi M, Nakashima O, Miyaaki H, Fujimoto $M$ and Kojiro $M$ Clinicopathological study of scirrhous hepatocellular carcinoma. J Gastroenterol Hepatol 21: 1470-1477, 2006

12. Yang R, Rescorla FJ, Reilly CR, et al: A reproducible rat liver cancer model for experimental therapy: introducing a technique of intrahepatic tumor implantation. J Surg Res 52: 193-198, 1992.

13. Freise CE, Liu T, Ascher NL and Roberts JP: Hepatotoxins and liver transplantation decrease pulmonary metastases in rats with hepatoma. J Surg Res 64: 198-202, 1996.

14. Forbes SJ, Russo FP, Rey V, et al: A significant proportion of myofibroblasts are of bone marrow origin in human liver fibrosis. Gastroenterology 126: 955-963, 2004.

15. Sham RL, Packman CH, Abboud CN and Lichtman MA: Signal transduction and the regulation of actin conformation during myeloid maturation: studies in HL60 cells. Blood 77: 363-370, 1991.

16. Ogawa $\mathrm{T}$, Tateno $\mathrm{C}$, Asahina $\mathrm{K}$, et al: Identification of vitamin A-free cells in a stellate cell-enriched fraction of normal rat liver as myofibroblasts. Histochem Cell Biol 127: 161-174, 2007.

17. Ikeda K, Wakahara T, Wang YQ, Kadoya H, Kawada N and Kaneda K: In vitro migratory potential of rat quiescent hepatic stellate cells and its augmentation by cell activation. Hepatology 29: 1760-1767, 1999.

18. Lu L, McCaslin D, Starzl TE and Thomson AW: Bone marrow-derived dendritic cell progenitors (NLDC $145^{+}, \mathrm{MHC}$ class $\left.\mathrm{II}^{+}, \mathrm{B} 7-1^{\mathrm{dim}}, \mathrm{B} 7-2^{-}\right)$induce alloantigen-specific hyporesponsiveness in murine $\mathrm{T}$ lymphocytes. Transplantation 60 : 1539-1545, 1995.

19. Lee JI, Paik YH, Lee KS, et al: A peroxisome-proliferator activated receptor- $\gamma$ ligand could regulate the expression of leptin receptor on human hepatic stellate cells. Histochem Cell Biol 127: 495-502, 2007.

20. Witz IP and Levy-Nissenbaum O: The tumor microenvironment in the post-PAGET era. Cancer Lett 242: 1-10, 2006.

21. Kalluri R and Zeisberg M: Fibroblasts in cancer. Nat Rev Cancer 6: 392-401, 2006.

22. Pinzani M, Rombouts K and Colagrande S: Fibrosis in chronic liver diseases: diagnosis and management. J Hepatol 42: S22-S36, 2005.

23. D'Ovidio KL, Trucksess MW, Devries JW and Bean G: Effects of irradiation on fungi and fumonisin $\mathrm{B}(1)$ in corn, and of microwave-popping on fumonisins in popcorn. Food Addit Contam 24: 735-743, 2007
24. Winau F, Hegasy G, Weiskirchen R, et al: Ito cells are liverresident antigen-presenting cells for activating $\mathrm{T}$ cell responses. Immunity 26: 117-129, 2007.

25. Milik AM, Buechner-Maxwell VA, Sonstein J, et al: Lung lymphocyte elimination by apoptosis in the murine response to intratracheal particulate antigen. J Clin Invest 99: 1082-1091, 1997.

26. Van Parijs L and Abbas AK: Homeostasis and self-tolerance in the immune system: turning lymphocytes off. Science 280 243-248, 1998.

27. Amann T, Bataille F, Spruss T, et al: Activated hepatic stellate cells promote tumorigenicity of hepatocellular carcinoma. Cancer Sci 100: 646-653, 2009.

28. Parmiani G and Anichini A: T cell infiltration and prognosis in HCC patients. J Hepatol 45: 178-181, 2006.

29. Hirano S, Iwashita Y, Sasaki A, Kai S, Ohta M and Kitano S: Increased mRNA expression of chemokines in hepatocellular carcinoma with tumor-infiltrating lymphocytes. J Gastroenterol Hepatol 22: 690-696, 2007.

30. Saio M, Radoja S, Marino M and Frey AB: Tumor-infiltrating macrophages induce apoptosis in activated CD8(+) $\mathrm{T}$ cells by a mechanism requiring cell contact and mediated by both the cell-associated form of TNF and nitric oxide. Immunol 167: 5583-5593, 2001.

31. Smith DJ, McGuire MJ, Tocci MJ and Thiele DL: IL-1 beta convertase (ICE) does not play a requisite role in apoptosis induced in T lymphoblasts by Fas-dependent or Fas-independent CTL effector mechanisms. J Immunol 158: 163-170, 1997.

32. Faisal W, Symonds P, Panjwani S, Heng Y and Murray JC: Cell-surface associated p43/endothelial-monocyte-activatingpolypeptide-II in hepatocellular carcinoma cells induces apoptosis in T-lymphocytes. Asian J Surg 30: 13-22, 2007.

33. Abraham D, Bou-Gharios G, Tulip G, Sumner H and Olsen I: Regulation of CD2-mediated heterotypic interactions of murine T lymphocytes. Cell Immunol 156: 342-356, 1994.

34. Crowston JG, Salmon M, Khaw PT and Akbar AN: T-lymphocyte-fibroblast interactions. Biochem Soc Trans 25: 529-531, 1997.

35. Yarovinsky TO and Hunninghake GW: Lung fibroblasts inhibit activation-induced death of T cells through PGE(2)-dependent mechanisms. Am J Physiol Lung Cell Mol Physiol 281: L1248-L1256, 2001.

36. Kristensen DB, Kawada N, Imamura K, et al: Proteome analysis of rat hepatic stellate cells. Hepatology 32: 268-277, 2000.

37. Santucci L, Fiorucci S, Cammilleri F, Servillo G, Federici B and Morelli A: Galectin-1 exerts immunomodulatory and protective effects on concanavalin A-induced hepatitis in mice. Hepatology 31: 399-406, 2000

38. Chen D, McKallip RJ, Zeytun A, et al: CD44-deficient mice exhibit enhanced hepatitis after concanavalin A injection: evidence for involvement of CD44 in activation-induced cell death. J Immunol 166: 5889-5897, 2001.

39. Hellerbrand, Wang SC, Tsukamoto H, Brenner DA and Rippe RA: Expression of intracellular adhesion molecule 1 by activated hepatic stellate cells. Hepatology 24: 670-676, 1996. 